\title{
Mesoscale FEM model for the analysis of composite delamination
}

\author{
Mezoskalowy model MES \\ do analizy delaminacji kompozytu
}

JERZY MARSZAŁEK JACEK STADNICKI

\begin{abstract}
The article discusses the problem of delamination of layered composite specimens according to the mode I (tensile opening mode). It includes the experimental part, which sets the averaged characteristics of delamination of the specimens in the relation tensile opening-tensile force as well as the description of mesoscale FE model of composite, which takes into account its internal structure. The model was used in the simulation of delamination, while the development of the fracture took place in consequence of modifications of finite elements modeling the matrix. The results of the delamination simulation with the use of the developed FE model were consistent with the results of the experiment.
\end{abstract}

\section{KEYWORDS: computer modeling, layered composite, experimental studies, FEM analysis, internal structure of the composite}

Polymer composite materials with a laminar structure (laminates) are characterized by: high mechanical strength with low own weight, corrosion resistance and satisfactory thermal stability. Due to these properties, they are used as construction materials in many fields, including aviation and automotive technology as well as in the production of boat parts and hulls. The macroscopic behavior of the laminate depends primarily on the number and orientation of layers and material of the components. Layered composite has the highest tensile strength in the direction of the reinforcement layers, while it is less durable across.

The most common form of damage to such a composite is delamination, which consists in breaking the cohesion of the matrix between the layers of reinforcement. The criterion for delamination may be exceeding of the limit value of deformation or boundary stress in the matrix. For the simulation of such a process, the finite element method is successfully used. Due to the anisotropy of composites, it is required to prepare a discrete model with properly defined engineering constants. Because the FE model of the composite should be sufficiently numerically effective, a model was proposed to simulate delamination, in which the smallest repetitive element of the structure is so-called repetitive unit cell (RUC). Taking into account the number of finite elements included in the model, it can be called a mesoscale $[1,2]$.

\footnotetext{
* Mgr inż. Jerzy Marszałek (jmarszalek@ath.bielsko.pl), prof. dr hab. inż.Jacek Stadnicki (jstadnicki@ath.bielsko.pl) - Akademia Techniczno-Humanistyczna w Bielsku-Białej
}

DOI: https://doi.org/10.17814/mechanik.2017.7.83

\section{Experimental delamination of composite according} to the first mode of fracture

The first mode of fracture is used to determine the resistance of a composite to breaking the cohesion between layers due to exceeding the permissible value of normal stress in the matrix. The tests may be performed using the DCB method (double cantilever beam test), described in detail in ASTM D5528 or, for example, in [3]. Delamination of the composite is carried out on a flat specimens with dimensions $L \times B \times 2 h$ (fig. 1). Due to the specific way of conducting the tests, it was necessary to glue the steel blocks with dimensions of $10 \times 10 \times 20 \mathrm{~mm}$ with through holes of $\varnothing 5 \mathrm{~mm}$ to the specimens, to which the connecting pins were introduced with the holders of the testing machine. Each specimen was made of 16 layers of plain weave fabric made of carbon fiber tows and epoxy resin. The fabric layers in the composite were arranged in such a way that the reinforcement tows ran parallel to the edge of the specimen. During the production of specimens, between the reinforcement layers adjacent to the symmetry plane of the specimen ( $x y$ - fig. 1), a thin film was placed, which prevented their permanent connection. This allowed the foil to separate the upper part of the specimen from the lower one over the length $a_{0}$ and thereby initiate precrack. A weight analysis of ten specimens showed that the carbon fiber fabric was $58.5 \pm 0.6 \%$ of the composite weight. The delamination tests were performed on a universal testing machine Inspekt Table Blue 5. During tests, the speed of moving crosshead of the testing machine was set at $0.5 \mathrm{~mm} / \mathrm{min}$. The set value was the specimen opening $\delta$, and the measured value - $P$ force value (fig. 1). The tests were repeated for 15 composite specimens.

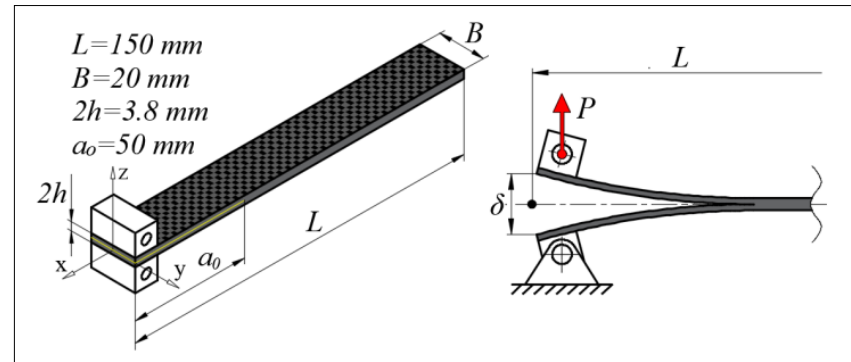

Fig. 1. Dimensions of the composite specimen and parameters of the DCB test

Based on the measurement protocols, the delamination characteristics $P(\delta)$ of each specimen were determined - three exemplary characteristics are shown in fig. 2a. In each case, the characteristics can be distinguished by two phases. Phase I represents the 
linear part, in which the pre-crack does not propagate and the specimen accumulates the potential energy of elastic deformation. In phase II, from the end of precrack, it begins to propagate the crack, where the $\delta$ changes in steps as a function of the force $P$, and between the step variations of the opening, the relationship $P(\delta)$ is linear. The characteristics of individual specimens differ, although they maintain a clear similarity to the nature of the course. The discrepancies can be caused by random arrangement of structure defects or various resin filling in the separated layer. Compared to the results of tests carried out within the work [4], a better agreement of the delamination characteristics was obtained, because during preparation of the specimens, attention was paid to the accuracy of preparing and gluing of the steel blocks acting as handles. It is important that axes of the through holes in the steel blocks glued to the specimens are parallel to the front of the pre-crack. Failure to meet this condition leads to an oblique arrangement of the specimen, so that the normal stress in front of the pre-crack are unevenly and interfere with the delamination process. On the basis of 15 characteristics, an average stiffness curve for the linear part was prepared (fig. 2b). After exceeding the critical force $P_{M A X}$, which corresponds to the MAX point on the characteristic, delamination begins and the force $P$ drops to the point $A$. The graph for the MAX point gives value of the force $P_{M A X}$ and opening $\delta_{M A X}$ along with the confidence intervals for the significance level 0.05 according to the t-Student test.

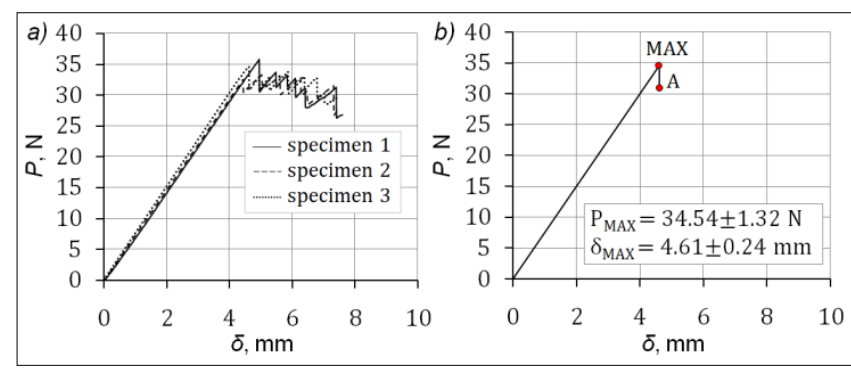

Fig. 2. Delamination characteristics: a) for three specimens, b) averaged for all specimens for the linear part

\section{Mesoscale FE model of composite}

Simulation of delamination of a composite specimen was carried out using FEM. For this purpose, a mesoscale model was developed that mapped the internal structure of the composite and took into account the volume proportions of the components, while maintaining the separation of the reinforcement and matrix phases. Construction of the model began with the identification of structure repeatedly reproduced in the fabric, the so-called repetitive unit cell (fig. 3a). Woven fabric made from fiber tows was brought to the plane, which meant that the modeling of a single cell required the use of four nodes located at the interlacing points of fiber tows. Structure of the composite was represented by finite elements of beam type 1D Beam and surface 2D Shell (fig. 3b). Fiber tows between the nodes and resin connecting the fabric layers were modeled with beam elements. Two-dimensional finite elements were used to include the resin filling the space between the fiber tows of the repetitive unit cell in the model.

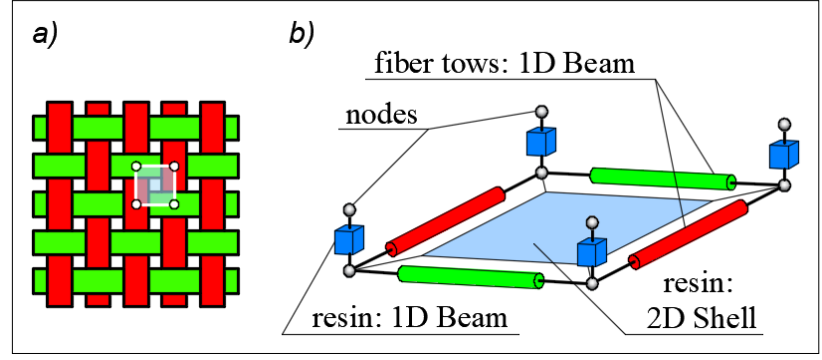

Fig. 3. Repetitive unit cell of the composite: a) marked on the fabric, $b$ ) in the form of the FE model

One of the commonly used methods of modeling the delamination process is the use of a cohesive zone in the model. It consists in introducing special finite elements (cohesive) between layers of the discrete model, whose properties enable modeling of initiation and further propagation of the crack. Depending on the delamination mode, the use of a cohesive element requires defining the relationship between stresses and relative displacements. Therefore, the cohesive elements may have different characteristics (traction-separation curves), of which the bilinear method is most often used. In phase I, the stress in the cohesive element grows linearly as a function of the displacement of nodes until reaching the threshold value, and then in phase II, the slope of the characteristic changes so that the stress in the element decreases as a function of displacement of nodes. Phase II corresponds to the weakening of the material. Separation of two adjacent layers occurs when the stress in the cohesive element is zero (separation phase). As a consequence, delamination results in a complete loss of stiffness of the cohesive elements.

A similar scheme was used in the mesoscale model. The crack growth was ensured by changing the values of the parameters determining the stiffness of the stretched beam elements modeling the resin in the cracking zone (the cross-section area or Young's modulus was changed). This assumption required development of an appropriate algorithm to control the delamination simulation of the composite FE model. The algorithm detected beam elements modeling the resin between the reinforcement layers, in which the threshold value of strain $\varepsilon_{k}$ was exceeded, and modified (significantly reduced) their stiffness. Modification consisted in the fact that for a beam element placed between nodes $i$ and $j$ (fig. 4), for which $\varepsilon>\varepsilon_{k}$, the cross-section (or Young's modulus) assumed a very small value in relation to the initial value.

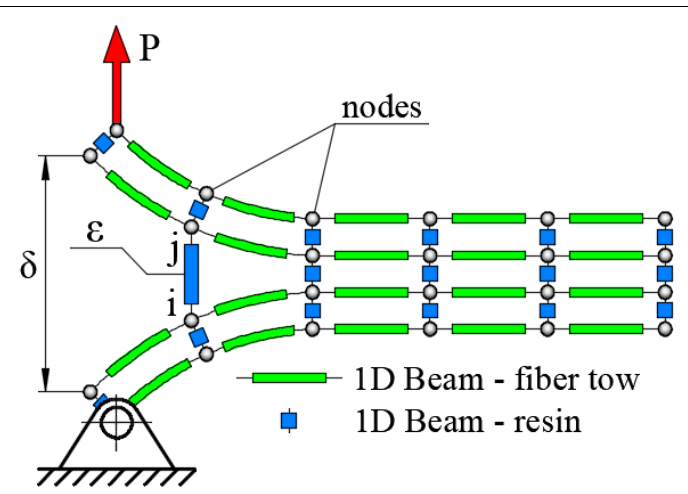

Fig. 4. Diagram of the delamination of the mesoscale model 
The threshold strain value $\varepsilon_{k}$ was determined based on the simulation of the FE model of the composite specimen, which consisted in the simulation of the experiment. For the delamination corresponding to the MAX point of the averaged experimental characteristic (fig. 2b), the strain value $\varepsilon_{k}$ in the beam elements modeling the resin between the reinforcement layers in front of the pre-crack, was read.

\section{Simulation of delamination process}

In order to automate the creation of FE models of flat composite specimens, a special program was developed in the APDL command language, which is the internal language of the Ansys system. The program acts as a generator of nodes and finite elements according to the definition of a repetitive unit cell (fig. $3 b$ ). The advantage of the program is the ability to generate models with variable thickness, and number and orientation of layers. Positions of the nodes resulted from the dimensions of the specimens and position of the interlacing points of the reinforcement fiber tows. The cross-sectional parameters of the 1D Beam188 elements and the thickness of the 2D Shell63 elements of the repetitive unit cell were determined on the basis of its dimensions, the distance of layers in the composite and weight fraction (volume fraction) of the components. The model consisted of 16 layers. According to fig. 1, at length $a_{0}=$ $50 \mathrm{~mm}$, vertical beam elements modeling the resin between the middle layers were removed in order to modeling the pre-crack. FEM calculations were carried out taking into account the boundary conditions in experimental studies. Thus, two additional nodes were created in the middle of the width of the model, the position of which corresponded to the axes of the holes of the steel blocks glued to the specimens (fig. 5). These nodes are connected by rigid elements of MPC184 type with nodes located on the top and bottom surface of the model. These surfaces corresponded to places where the steel blocks were glued. In the first node, only one degree of freedom is left to allow rotation relative to the hole axis of the block. In the second node, it was possible to move in the direction corresponding to the direction of movement of the crosshead of testing machine and the rotation relative to the axis of the hole.

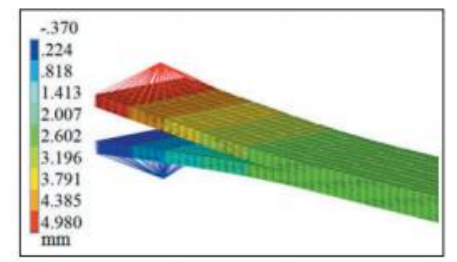

Fig. 5. Deformed discrete model of a composite specimen with pre-crack

On the basis of technology sheets, engineering constants of the components were adopted: Young's modulus of carbon fiber tows $E_{c}=105 \mathrm{GPa}$ and epoxy resin $E_{z}=3.4 \mathrm{GPa}$, Poisson's ratio of fiber tows $v_{c}=0.1$ and resin $v_{z}=0.35$. During the simulation with set step $\Delta \delta$ in each iteration, the condition of selecting and modifying the cross-section of beam elements modeling the resin between layers, was checked.

\section{Analysis of results}

Based on the FE simulation of the delamination of a composite specimen model was obtained the loaddisplacement curve at the node indicating the place of the specimen connection with the crosshead gripper of the testing machine. The computational characteristic was compared with results of experimental tests for selected three composite specimens (fig. 6). A very good agreement was obtained (correlation coefficient of characteristics in the linear part of $R^{2}=0.99$ ). Crack propagation in the model proceeded in jumps, as in the specimens during the experiment, with equal intervals between successive jumps. Such a way of propagation of delamination resulted from the regular construction of the model. In addition, the model did not include stochastic factors, e.g. local micro-defects in structure of composite specimens.

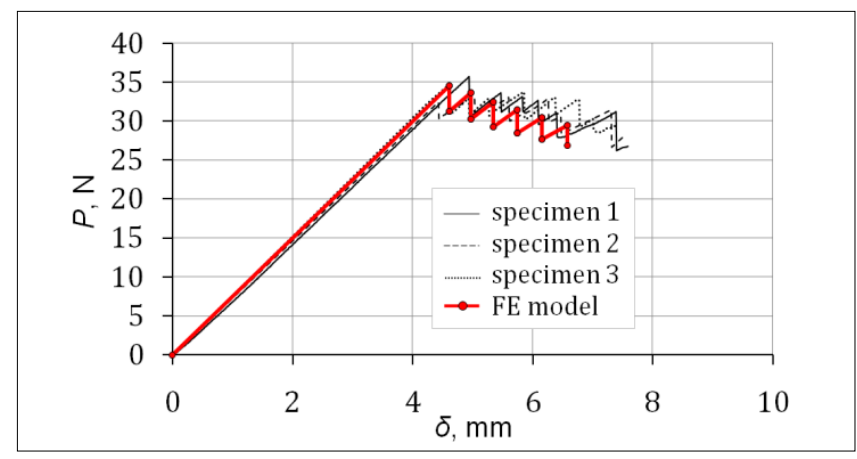

Fig. 6. Comparison of experimental and computational characteristics

\section{Conclusions}

The paper presents the author's mesoscale FE model of a layered composite reinforced with a plain weave fabric made of carbon fiber tows, designed to simulate the phenomenon of delamination of a composite according to the first mode of fracture (opening mode). The model and the procedure for modifying the stiffness (cross-section) of beam elements that model the resin joint of reinforcement layers eliminate the need to create a cohesive zone, which is usually used for fracture modeling. Discrete models with cohesive elements allow analysis of crack propagation only in places where a cohesive zone is defined. In the proposed mesoscale model - due to its structure - break of the composite's consistency after fulfilling the appropriate criterion can take place anywhere, so there is no need to know the location of potential fracture places. An important advantage of the developed model, taking into account the internal structure at the component level and the separateness of their phases, is also the ability to analyze the strength of the composite due to resin cracking or tearing the reinforcement fiber tows, which in turn is not possible in the case of single-phase FE models with so-called sandwich elements, intended for modeling composites available in FEM preprocessors. In addition, it is possible to determine the stiffness of composite parts that have been weakened by cracks, but have not been completely destroyed and can be further used under a lesser load. 


\section{REFERENCES}

1. Marszałek J., Stadnicki J. „Walidacja doświadczalna modelu MESkompozytu warstwowego wzmocnionego tkaniną". Inżynier XXI wieku. Akademia TechnicznoHumanistyczna w Bielsku-Białej, 2016, pp. 707-718.

2. Stadnicki J., Tokarz Z. "Mesoscale finite element model for calculatingdeformations of laminate composite constructions". Advances in Mechanical Engineering. 8, 2 (2016): pp. 1-9.

3. Carlsson L.A., Adams D.F., Pipes R.B. "Experimental characterizationof advanced composite materials". Fourthedition. BocaRaton: CRCPress - Taylor \& Francis Group, 2014.

4. Stadnicki J., Marszałek J. „Doświadczalne badanie delaminacji kompozytu warstwowego według I I II schematu pękania". Mechanik.7 (2016): pp. 818-819. 